\title{
O ESPAÇO GEOGRÁFICO COMO UM FATOR DEFINIDOR DO DESIGN: O BIQUÍNI NA CIDADE DO RIO DE JANEIRO
}

Adriana Sampaio Leite

Professora Adjunta Graduação em Design PUC-Rio

adrianasleites@gmail.com

Resumo: O Rio de Janeiro estabeleceu-se como um centro urbano debruçado sobre a faixa oceânica. Desse modo, cultivou uma cultura balneária que, a partir de diversos vetores, findou por definir um tipo de design de moda muito relacionado ao uso dos espaços praianos. Neste artigo apontamos o processo de caracterização do biquíni como um objeto de moda genuinamente carioca.

Palavras-chave: Design; Rio de janeiro; Praia; Biquíni

Abstract: Rio De Janeiro was configured as an urban center on the oceanic band, in this manner cultivated a balneal culture, where diverse vectors finished defining a type of fashion design, closely related to the spaces of the beach in this article we present the bikini configuration process as Rio genuine fashion object.

Keywords: Design; Rio de janeiro; Beach; Bikini 


\section{INTRODUÇÃO}

Este artigo tem a intenção de discutir a constituição de objetos de design em que o espaço geográfico é um vetor essencial. Para isso estabelecemos respectivamente, a cidade do Rio de Janeiro e o traje de banho biquíni, como o lugar e o objeto a serem estudados.

Partimos da perspectiva da geografia humana, que entende a experiência do homem convivendo em grupo sobre o espaço como veículo da constituição de lugares significados, os quais são construídos através da relação humana com o meio.

Refletimos sobre a conformação da cidade do Rio de Janeiro e como se delineou o uso do espaço de praia na constituição de uma identidade e corporeidade praiana.

Como nosso ponto crucial é discutir a relação da conformação dos objetos e o lugar de onde surgem, buscamos apoio nos estudos etnográficos de André LeroiGourhan, que discutem as diversas técnicas geradas em tempos e espaços diferenciados, inclusive as mais elementares, capazes de germinar no mundo diversos objetos. Uma vasta pesquisa iconográfica entre a primeira década do século XX e o ano de 2012, também foi desenvolvida. A pesquisa se utilizou de publicações que que bem representaram a cidade do Rio de Janeiro, tais quais: as revistas Careta, O Cruzeiro e Manchete, os jornais $O$ Pasquim e Jornal do Brasil, e o arquivo de fotos do jornal Correio da Manhã.

Por fim, apontamos o momento e o lugar onde o objeto biquíni se abrasileirou definitivamente, constituindo novas formas, que o definiram como um objeto de moda genuinamente brasileiro.

\section{ESPAÇO E LUGAR}

Os vocábulos - espaço e lugar, remetem à ideia de situação e localização. Contudo, seus significados podem ser diferenciados dependendo de como são vivenciados. Neste trabalho, utilizaremos a perspectiva de uma geografia que se constrói a partir de uma experiência do sujeito associada à distinção cunhada pelo geógrafo sino-americano Yi-fu Tuan (2013) - entre espaço indiferenciado e lugar significado -, em que o primeiro termo define-se por uma espacialidade isenta da ação humana, ampla e livre, enquanto, o segundo, revela-se por um espaço experienciado pelo homem através de interações e interferências, tornando-se, então, lugar significado.

Ao interagir no espaço, o homem produz objetos que, ao se integrarem na natureza, estabelecem uma nova organização espacial definindo assim um lugar. A partir do lugar é possível estabelecer a paisagem, que, a princípio, será sempre singular, porém poderá ser lida e descrita de maneira múltipla, sob cada olhar particular. Sua percepção é subjetiva embora sua materialidade seja objetiva.

A escolha do homem comum em relação a ações que empreende sobre o espaço é limitada. Sua participação se faz mediante sua corporeidade, que viabiliza o processo da ação. Destarte, empreendendo-se a ação no lugar definido pela paisagem, a corporeidade se integrará às formas da natureza, aos objetos incorporados a ela e aos valores culturais vigentes. Portanto, a situação espacial influenciará no tipo de ação empreendida pelo corpo e, consequentemente, influenciará também no gestual e na forma, tanto do corpo quanto nas intervenções formais feitas pelo homem sobre o 
corpo, como as vestimentas.

Pertencendo a espaços habitados e sujeitas à ação do homem, os lugares estarão sujeitos a objetos ${ }^{1}$ construídos pelo homem por meio da técnica, considerando que "as técnicas são um conjunto de meios instrumentais e sociais, com os quais o homem realiza sua vida." (SANTOS, 2008, p. 67).

O homem é um criador de lugares e construtor de paisagens e as cria a partir de diferenciados artefatos, mediante uma malha de técnicas que coexistem e se alteram com o tempo. Na perspectiva de Leroi-Gourhan (LEROI-GOURHAN, 1971), as técnicas não ocorrem em um bloco sólido que se movimenta em ritmo constante, ao longo dos séculos. Elas se aprimoram e/ou se transformam em ritmo desigual, passando por fases de estagnação e de transformações irregulares. Algumas são mais dinâmicas e outras mais estáveis, não existindo uma lógica racional linear para explicar escolhas feitas pelos povos ao aderirem a um determinado tipo de técnica.

O autor nomina os objetos "artificiais", e os saberes sobre os mesmos de tecnologia, e entende esta como uma "membrana interposta" que intermedeia a interação do homem com seu meio natural.

Cada espaço, com diferentes características geográficas, propiciará diferentes resultados para os objetos tecnológicos, embora a tecnologia em si, ou seja, a maneira de fazer, possa ser a mesma. Cada lugar constituirá um padrão de "membrana interposta" em função de sua condição geográfica. Por exemplo, a cestaria hindu pode ser tramada de um mesmo modo que a cestaria ameríndia, no entanto as fibras utilizadas podem ser de outra espécie vegetal, gerando uma aparência diferenciada em função da adequação da fibra ao tramado, mas a estrutura tecnológica (aqui faz-se entender o seu hard-core ${ }^{2}$ ) será, basicamente, a mesma.

Desse modo, os objetos do vestuário, que, para Gourhan constituem uma técnica estável, são frutos de um relacionamento entre o homem e seu espaço geográfico em sua completude, tais quais: clima, estrutura geológica, vegetação, recursos hídricos, vida animal, enfim, todos os elementos que o compõe.

Tais objetos imprimem, em sua configuração e em seu uso, elementos que indicam o seu sítio de pertencimento ${ }^{3}$ (ZAUOAL, 2006), seja através de matéria-prima, seja por tecnologia ou por ser fruto do comportamento do grupo e de pessoas em relação ao seu lugar. Todavia, sabendo-se que a moda hoje é um fenômeno alinhado globalmente, nota-se ainda que cada cultura, quando consegue introduzir sua moda genuína dentro do circuito global, imprime, no grande sistema, a sua marca que traz gravado o seu sítio de pertencimento. Esse grifo garante, dentro da massa global em que a moda se transformou, mostrar a originalidade e a força de cada lugar que

\footnotetext{
${ }^{1}$ Aqui o sentido de objeto diz de tudo que apresenta materialidade.

${ }^{2}$ Entendemos hard-core, como a estrutura mínima da técnica utilizada. No caso da cestaria referimo-nos à trama que possibilita a confecção de uma superfície. Contudo, a aparência da superfície dependerá do tipo de ponto a ser dado, que também dependerá da capacidade do material aderir ou não àquele ponto.

${ }^{3}$ Combina a referência espacial a outras variáveis, sobretudo culturais, considerando, acima de tudo, o grupo atuando em espaços coletivos e históricos e suas interações para construir a categoria território, ou mais exatamente, sítio de pertencimento. Os Sítios situam o ser humano em contexto de acolhimento, solidariedade e compromisso com os saberes locais. "O Sítio de Pertencimento resulta de um sistema de crenças e práticas herdadas da trajetória do grupo humano considerado. Assim, o Sítio é um território imaginário no qual se encaixa o saber da organização em questão" (ZAOUAL, 2006, p. 213).
} 
conseguiu estabelecer seu diferencial.

Sabe-se que a cultura ocidental buscou, através de diversos processos colonizadores, se estabelecer como hegemônica produzindo uma "história única", e a moda enquanto fenômeno, traz em seu cerne esta perspectiva.

No Brasil, as forças de influência são mantidas ainda hoje, e um dos fatores que apontamos para tal procedimento remonta às origens da colonização e remete também à forma como se deu o processo de urbanização do Brasil, que viu suas cidades se desenharem a partir de uma organização imposta pela metrópole colonizadora: o poder se instalou em um ponto central e as outras camadas da cidade surgiram a sua volta. Os espaços estabelecidos por cada camada demonstram limites muito demarcados. O centro, lugar do poder, é amarrado por uma rede de proteção forte que não propicia a troca entre os outros círculos que o inscrevem. O que determina a rede de proteção é o acesso à língua escrita. É ela que escritura os papéis que comprovam a posse das terras, nas quais são inscritos os círculos definindo quem tem domínio sobre o lugar (RAMA, 1985).

Assim, os hábitos vestimentares do brasileiro se mantiveram pautados pela apreensão de um repertório originário de culturas hegemônicas, o que fez perpetuar sua condição de "colônia" e copista por muito tempo. Sem dúvida, esse procedimento foi alimentado, sobretudo, pelo grupo de pessoas circunscritas ao centro do poder ${ }^{4}$, na cidade escriturária, e que apostavam na estética colonizadora como sendo a única possível, a verdadeira e exclusiva forma de se vestir, isso porque lhes garantia a aceitação e a permanência no centro do poder.

As roupas e os acessórios eram importados ou copiados inteiramente. Contudo, outra camada social paralela àquela dos "colonizadores", circunscrita à faixa que pertence ao círculo central das cidades, construiu paulatinamente um repertório vestimentar feito a partir da composição entre índios, europeus e africanos, que, ao se misturarem, sujeitam seu patrimônio vestimentar às traduções, adaptações e apropriações, num jogo de troca múltipla, em que tudo se mistura provocando novas combinações e inaugurando uma corporeidade singular - tanto por meio da miscigenação como através da incorporação de hábitos uns dos outros.

Através do imbricamento das várias culturas presentes, o repertório popular atravessou o muro das cidades escriturárias. A transposição de elementos entre os diferentes corpos, com cores, estruturas e massas diferentes, desenhou, pelo uso, um modo de vestir peculiar, que atende um pouco mais aos requisitos propostos pela paisagem, pelo clima e pelos "modos de fazer" (tecnologias) existentes em solo nacional.

\section{A PRAIA E SEU USO PELOS HOMENS}

Enquanto paisagem, o mar e a praia já suscitaram as mais diversas leituras ao longo dos tempos. Entretanto, o entendimento da paisagem praiana como área de convívio na cultura ocidental se desenvolveu a partir do século XVIII.

A vivência do banho é naturalmente humana, mas, na constituição da civilização ocidental, principalmente nos espaços urbanos, o desfrute dos ambientes

\footnotetext{
${ }^{4}$ Ressalta-se que a partir da chegada da corte portuguesa, em 1808, no Rio de Janeiro, onde instalou a sede do Império, o referido grupo reproduzia na íntegra todo o protocolo. comportamental utilizado pela corte, baseado na boa sociedade francesa, inclusive com relação aos hábitos vestimentares.
} 
áqueos cai em desuso por um tempo e, durante o processo civilizatório, torna-se atitude imoral.

A retomada do uso da praia como espaço de saúde e lazer, redundará em um processo de adequação de sensações e hábitos. O pisar na areia não é habitual: a textura, ora seca, ora molhada, apresenta, por vezes, granulações díspares na faixa entre a água e a terra firme. Tudo é novidade e experimentação.

Em decorrência desse fato, surge um apanágio de objetos e rituais, que passam a ser utilizados para intermediar a relação do homem com o cenário da praia. Os novos aparatos são produzidos para responder a uma demanda aparentemente funcional, inventada, proveniente de uma série de comportamentos codificados pelo processo civilizatório.

Inicialmente, a roupa apropriada para o banho de mar não se apresenta sob a lógica funcional aos olhos de hoje. Sua suposta funcionalidade relaciona-se à proteção do frio ${ }^{5}$ e busca, na verdade, atender às normas reguladas pelo pudor e pelo medo da violação ocular.

A percepção do mundo ocidental foi codificada em história, registrada, repetida e relembrada a cada instante. Tornou-se hegemônica e acomodou-se sobre diversos outros espaços, para além da Europa. Sobrepôs camadas de experiências acumuladas de outras culturas, em um projeto que contou com a estratificação das sociedades em grupos sociais com forças díspares, em que, as mais poderosas impingiram às outras seus hábitos e suas formas culturais. Contudo, isso não significou que as primeiras camadas, presas ao solo, não tivessem transpirado e imprimido traços, ainda que sutis (em momentos de hegemonia forçada das culturas ocidentais), mas fundamentais, para constituir personalidade cultural.

A herança sempre está presente na constituição desses espaços, mesmo que escamoteada por descrições subjetivas que reforçam sua negação. Não nos resta dúvida de que o processo civilizatório empreendido pelas classes detentoras do poder encontra mecanismos capazes de sufocar e esconder qualquer manifestação mais genuína, nativa, principalmente quando dissimulada atrás do sentido de pudor aliado à preservação do indivíduo no privilégio de sua intimidade ${ }^{6}$.

A despeito disso, nos trópicos, mais precisamente em terras brasilis, quando os ocidentais, vestidos, aqui desembarcaram, homens e mulheres, velhos e crianças andavam de um lado para outro sobre paisagem de exuberante natureza tropical, sem nenhum senso de pudor. Expunham o corpo mostrando, inclusive, as "vergonhas".

Os portugueses, entenderam que, toda aquela gente, muito à vontade, exibia o corpo, a seus olhos, completamente nus! Contudo, esses índios, como descreve Pero Vaz de Caminha, na carta a Manuel por ocasião do "achamento"7, assim como os europeus, também traziam seus corpos cobertos, mas com outro material, diferente do pano. Eles traziam seus corpos "vestidos" por pinturas acompanhadas, às vezes, de pequenas peças de indumentária e de adereços. Os elementos que constituíam a aparência dos nativos, além de consistir em natureza bem diferente dos utilizados

\footnotetext{
${ }^{5} \mathrm{O}$ que fez com que fossem confeccionadas em tecidos pesados, até mesmo lã.

${ }^{6}$ Norbert Elias afirma, em Processo Civilizador, que "não menos característico de um processo civilizador que a 'racionalização' é a peculiar modelação da economia das pulsões que conhecemos pelos nomes de 'vergonha' e 'repugnância' ou embaraço'. (ELIAS, 1993, p. 242)

${ }^{7}$ Carta escrita por Pero Vaz de Caminha dirigida a D. Manuel, conforme a leitura paleográfica pelo doutor Antônio Baião, recebe o nome, como documento, de "Carta do achamento do Brasil". (TINHORÃO, 2000, p. 160)
} 
pelos europeus, se organizavam sobre o corpo de maneira singular.

A princípio, a aparência inspirava um sentido econômico, simples. Entretanto, tal simplicidade inspirava formas elaboradas, tanto no que diz respeito às pinturas corporais como em relação aos adornos ${ }^{8}$. Porém, o ponto de vista empreendido pelos colonizadores não considerou nenhuma elaboração na forma como os nativos ornavam o corpo. O que marcou e ficou registrado na escrita de Pero Vaz de Caminha, não foi o tipo físico, diferenciado dos europeus, e nem a forma dos índios se apresentarem com suas indumentárias. O que sobressalta é o fato de estarem, ali, na descrição de Caminha "[...] 18 ou 20 homens pardos, todos nus, sem nenhuma coisa que lhes cobrisse suas vergonhas." (TINHORÃO, 2000, p. 160).

\section{RIO DE JANEIRO SEU ESPAÇO URBANO E A FORMA DE VESTIR}

A cidade do Rio de Janeiro, hoje, apresenta algumas características muito particulares. Enquanto espaço urbano, propõe uma organização de múltiplos contrastes. Ao contrário da maioria das cidades, expõe suas veias abertas. Não escamoteia as diferenças. Arrisca. Em sua organização espacial, desenha ambientes desiguais que ocupam o mesmo perímetro urbano. Integra. Solicita um constante diálogo entre seus espaços - habitados e desabitados. Justapõe, opõe, tanto nos fatores naturais quanto nos socioeconômicos. Vai do silêncio das florestas urbanas ao burburinho do comércio em ambientes abertos ${ }^{9}$, da acomodação das favelas sobre a superfície - como espaço arquitetônico homogêneo - à opulência das edificações dos bairros da orla. Essas cercanias com aparências e sistematizações extremas tornam a cidade singular.

Essas características geram uma porosidade entre as inúmeras camadas urbanas que respiram e transpiram umas às outras, engendrando um modo de ser carioca, que determina também um modo de vestir.

Assim, pode-se entender que o espaço urbano do Rio de Janeiro revela um território cultural bem definido, que suscita uma autonomia nos resultados formal e conceitual dos objetos vestimentares utilizados em sua paisagem.

Assim, a cidade que adotou dentro das rodas oficiais os hábitos trazidos da Europa, definiu um contingente de pessoas longe deste círculo que se preservou da contaminação de hábitos estritamente europeus, cultivando uma resistência que não promovia embate, mas operava se infiltrando sutilmente pelo simples avizinhamento. Desse modo, há um contágio mútuo: de um lado, as regras de sociabilidade importadas da Europa, e obrigatórias, para pertencer ao quadro oficial da cidade; do outro, a verve da festa, da dança, da música e também das crenças. Tudo isso gerava, dentro do espaço da cidade, um processo de transculturação ${ }^{10}$.

\footnotetext{
${ }^{8}$ Considerar que os índios não se vestiam pode ser um enorme equívoco. Na verdade, apenas a lógica da indumentária é outra, estabelecida por condições geográficas e tecnológicas que redundam em cultura. Portanto, um índio pintado pode ser um índio vestido por uma tinta.

${ }^{9}$ Apesar de o Rio de Janeiro ter aderido ao shopping-center fechado, uma boa quantidade de espaços comerciais se apresenta na cidade, dando uma característica mista de mercado árabe à configuração de feiras como o calçadão de Madureira o camelódromo da Uruguaiana, o Saara (centro da cidade) e Ipanema.

${ }^{10}$ Aqui entendemos, de acordo com Fernando Ortiz (1991), transculturação como o processo de apropriação dos materiais nativos pelos europeus e a apropriação por parte da colônia de elementos europeus, que passaram a constituir modos de representação na colônia - ou seja, sujeitam-se a novas
} 


\section{A CONQUISTA DAS PRAIAS AO SUL}

A formação da cidade do Rio de Janeiro ocorre em um processo de fora para dentro. Sendo o mar a porta de entrada para a terra, a cidade nasce debruçada sobre ele. Isso resultou em uma organização espacial, que produziu um tipo de comportamento sociocultural, que, ao ser processado ao longo do tempo, resultou em uma relação corpórea da população carioca com o entorno, definindo gestual e comportamento particulares.

Inicialmente a cidade colonial se instalou de costas para o mar, protegida pela baía. Na República, a elite urbana, fugindo do centro insalubre e buscando os ares saudáveis da praia, promoveu a ocupação na direção sul da cidade. Desse modo, como aponta Sabine Knierbein (KNIERBEIN, 2006), o desenvolvimento da zona sul da cidade sobre as praias foi proporcionado pela descoberta da vida balneária e pela especulação imobiliária, que viu, na possibilidade de criar bairros com melhor qualidade de vida, um excelente negócio; ou seja, os vetores que definiram o crescimento da cidade em direção às praias do Sul podem ser associados às dimensões cultural e econômica.

Os banhos de mar eram praticados inicialmente apenas como atividade curativa, feita nas casas de banho ${ }^{11}$. Eles só se constituíam hábito de lazer assumido quando se tornaram uma moda elegante entre os jovens, que, com a reforma urbana, puderam usufruir de um espaço codificado propício para o esporte, como a natação e as regatas, organizadas na praia de Botafogo.

A ocupação da orla seguiu um curso que desenhava sobre o mapa da cidade uma linha contínua, construída ao longo do tempo, entre o final do século XIX e a década de 1980, que partiu do centro seguindo em direção sul.

A geografia da cidade in natura na direção sul apresentava um desenho com alguns obstáculos: a faixa de ocupação possível era estreita, imprensada entre o mar e as montanhas, e a ocupação era paulatina e avançava sobre a orla do litoral Atlântico com apoio de políticas relacionadas ao implemento de condições viárias, transportes, planos urbanísticos e obras de engenharia.

A popularização do banho de mar inicia-se na praia do Boqueirão, ainda utilizando casas de banho como apoio intermediário, seguindo em direção ao Flamengo, depois Botafogo, Copacabana, Ipanema, Leblon e por fim o litoral em sentido sudoeste até a Barra da Tijuca e adjacências.

$\mathrm{O}$ aspecto cultural vigente, no início do século XX, de culto ao corpo pelo viés da saúde como estopim da ocupação, pela elite, da faixa litorânea sul, consolidou uma corporeidade já prospectada pela proximidade da orla, que ultrapassou a faixa de areia e tomou as ruas da cidade.

Este não é um fator único, embora seja o mais visível pela ótica da elite social. A ele, juntaram-se fatores, como as heranças das culturas africana e indígena. As intervenções promovidas pelo Estado no sentido de desenvolver a cidade e urbanizála, na maioria das vezes, afastavam as populações de menor renda do epicentro das reformas. Entretanto vale lembrar que no Brasil, o uso das águas, sejam elas de rio,

descrições, embora, aos olhos de todos, sejam lidos como originalmente europeus. Este conceito pode ser aprofundado no trabalho de Mary Louise Pratt mais especificamente em: Olhos do império: relatos de viagem e transculturação.

${ }^{11}$ As casas de banho seguiam os moldes europeus, e a primeira a ser instituída no Rio de janeiro foi na praia do Boqueirão, próxima ao centro da cidade. 
mar ou lagos, é entendido como de interesse público; desse modo o acesso à praia, não importa onde, é livre.

A cidade do Rio de Janeiro passou por um processo de urbanização que lidou com duas formas diferentes de ocupação de espaço: uma "contratual" estabelecida dentro do que Rama (1985) define como cidades escriturárias, em que se formaliza a posse da terra por normas e leis; e outra relativa à ocupação e posse dos espaços que se legitimam por meio de laços familiares e relações consolidadas por identidades culturais comunitárias que estabelecem vínculos territoriais. Nesse caso, é o sentimento de pertencimento ao grupo que outorga a posse ${ }^{12}$.

A tenacidade da parte da população menos favorecida em se manter nas áreas centro-sul da cidade fez com que a cidade acomodasse, dentro de um único círculo, várias camadas sociais, o que fermentou o processo de transculturação e produziu uma tradição inventada essencialmente carioca.

A praia desempenhou um papel crucial enquanto lugar do encontro social das diversas camadas. Nela, os corpos soltos, se apresentam desprovidos de armaduras sociais, já que os trajes apropriados para o banho não são segmentados - ele é único e para todos, e quando molhado, mesmo que não transpareça a pele, demostra o corpo. É na praia carioca que se encontram as laras, Marias e lemanjás.

\section{O LUGAR DO BIQUINI}

Em 1936, a alemã Mirian Etz usou, no Arpoador, o traje de banho em duas-peças trazido da Alemanha e em 1951, sobre o corpo da bailarina Hirene Hosko, viu-se pela primeira vez, na mesma praia, um biquíni, que, diferentemente do duas-peças, mostrava o umbigo.

Tais acontecimentos já plasmavam o papel do bairro para a constituição do biquíni brasileiro, e foi a partir de uma situação totalmente contingente que sobre suas areias pode-se localizar o processo do aparecimento de tal elemento de moda. Inicialmente as influências eram estrangeiras, vinham de países onde as mulheres conquistavam mais liberdade de escolha, não sendo sujeitas apenas ao papel de mãe, recatada e do lar. Entretanto, o tipo de cultura praiana que se estabeleceu nas praias cariocas, principalmente em Ipanema, ao longo do tempo, desencadeou um comportamento em relação a apropriação do corpo, o modo de vestir e o lugar, o que propiciou o redesenho do biquíni.

Foi em Ipanema, com a construção de um píer por volta de 1971, que nasceu um novo "ponto" da galera na praia. Para construí-lo foi necessário dragar a areia do mar, depositando-a na praia, criando enormes dunas que tapavam a visibilidade do que ocorria na beira da água para as pessoas que passavam na calçada.

Nesses tempos, o país vivia um momento político conturbado. "O Brasil andava sinistro. A repressão voava baixo. A polícia colada atrás. " (CHACAL, 1998, p. 19). E nada melhor do que curtir a praia protegido pelas dunas. Nessa circunstância, começou a se reunir ali "[...] um espécime feito de seres peludos, esqueléticos, com pouquíssima roupa e uma língua alada" quem não estava na onda ficava de pé. "Impressionante! Parecia uma tribo de zulus! Em pé, conversando. Sem parar. A cada

\footnotetext{
12 Gomes (GOMES, 2002) denomina essas duas formas de ocupação do espaço: a primeira "monoespaço", aquela relacionado às regras e leis; e a segunda o "geneoespaço", relacionada aos laços, genéticos ou sociais, espaços conquistados por grupos por intermédio da força da identidade cultural.
} 
onda que estourava a gente bolava um novo espetáculo. " (SIMÃO, apud CHACAL, 1998, p. 19)

O lugar ficou conhecido como Dunas do Barato e era frequentado por músicos, poetas, artistas plásticos, cineastas, atores e diretores de teatro, alguns ativistas políticos mais "odara", que ajudaram a construir ali um mundo fértil, deslocado dos enfrentamentos políticos diretos. Ali se produzia um pensamento paralelo, livre das amarras dialéticas: um mundo criativo.

Os surfistas, que viram quebrar no píer ondas perfeitas, conviviam com a galera, mas eram de outra tribo, e nem sempre tudo rolava na paz, vez ou outra dava quiproquó. $\mathrm{O}$ foco deles eram as ondas, já o do grupo que ficava nas dunas, eram as ideias. $\mathrm{O}$ encontro das turmas produziu resultados nos hábitos praianos. De um lado, o pessoal do surf, obcecado pelas ondas perfeitas do Havaí, reproduzia em seu modo de vestir um pouco da cultura da ilha do Pacífico e da Califórnia. Eram as bermudas floridas para os homens e as camisetas hang-ten. Do outro lado, aquelas roupas soltas, saiões compridos, batas, calças pantalonas de tecido de carne-seca, sandálias de dedo do mercado modelo ou da feira hippie, tudo meio em um visual hippie nacional, misturando elementos fortes das culturas regionais, notadamente a nordestina.

Os corpos eram assumidos sem grande pudor. De acordo com Chacal (1998) todos estavam, homens e mulheres, muito à vontade naquele espaço e se comportavam como se estivessem nus, e como que evocando seus antepassados nativos, faziam rodas para fumar o cachimbo da paz, revivendo rituais. Todo dia era dia de festa, todo dia era dia de índio, sem esquecer a turma do batuque da cruzada São Sebastião.

No "novo" espaço, escamoteado por suas dunas, produziu-se um oásis perfeito para os tempos de repressão. Dessa maneira, surgiu ali um novo modo de usar a praia. O casamento da turma do surf, que tinha como referência uma herança da cultura hippie californiana, com os filhos do movimento de Maio de 68, resultou em um comportamento que operava simultaneamente com "a política e o desbunde contracultural" (VILLAÇA, 2008. p.4.), assim possibilitou inovações de comportamento que resultaram em novos usos para objetos de vestuário já consagrados no espaço da praia, consolidando a praia como um território de produção cultural da cidade, desse modo, um "lançador" de moda.

O espaço era de liberdade, e a regência era dada pelo movimento da contracultura, que trazia em seu cerne questionamentos de jovens, de pessoas que buscavam o diferente. Nesse espaço se encontravam "o movimento hippie, a música rock, certa movimentação nas universidades, viagem de mochila e orientalismo. " (VILLAÇA, s.d.). O inusitado se fazia presente por toda a parte, seja na tentativa de topless, seja na atitude de enrolar o biquíni para evitar a marca de sol no quadril. Aliás, foi essa atitude, feita de um modo mais radical, que acabou criando a moda da tanga.

Na praia, todos buscavam uma cor bronzeada de verão, tanto que, ao invés de protetores solares, usavam-se os mais diversos óleos de bronzear. Algumas moças se deitavam para tomar sol abaixando as alças na frente, e de costas desabotoavam o sutiã, liberando toda a pele de qualquer empecilho. Quanto às partes de baixo do biquíni, que ainda era largo na lateral, costumava-se enrolá-la na altura do quadril, deixando a pele livre para o bronzeado. Esta atitude gerou paulatinamente a diminuição do biquíni, tornando-os pequeninos e muito puxados para cima do quadril.

Muitas jovens que não encontravam no mercado um tipo de biquíni que 
liberasse a lateral do corpo para queimar de sol confeccionavam-no em algodão, tricô ou crochê. A estrutura dessa roupa se simplificou ao máximo para facilitar a confecção caseira, e, as moças, em geral, muito magras, cortavam os tecidos modelando a parte de baixo como uma borboleta de asas triangulares e ajustando-os ao corpo por meio de amarrações de tiras nas laterais a ponto de atarem em forma de laço; enquanto que a parte de cima era literalmente formada por dois triângulos, cada um para um seio, também regulados por tiras que os prendiam em cada ponto do triângulo.

A liberdade instituída naquele território "escondido", atrás das dunas, não parou por ali: a pedra fundamental havia sido jogada, sem, claro, deixar de lado todo o processo desde os primeiros banhos, na forma de lazer, ocorridos na cidade, que já plasmavam um ambiente de descontração. Contudo, aqueles verões dos anos de 1970 conformaram uma identidade genuína, seja nos modos de comportamento, nas vestimentas ou nas novas gírias, e fizeram da praia um espaço criativo de cultura.

A validade do Píer acabou em 1974 com seu desmonte, e o ponto se deslocou para o posto nove, mais precisamente em frente ao hotel Sol Ipanema. No entanto, o Píer deixou sua marca. Lançou modas definitivas para a cultura carioca. Ali, na fala, nos hábitos e no corpo das mulheres víamos se consolidar o uso do biquíni tal qual conhecemos. Dali em diante, os biquínis nas praias do Rio de Janeiro ganharam definitivamente o design carioca.

\section{O BIQUÍNI CARIOCA}

Embora o biquíni tenha sido apresentado como uma invenção, na França, por volta de 1946, ele ainda tem tímida presença no Brasil na passagem da década de 1950 para a de 1960. Além disso, apresenta-se como uma novidade ainda não totalmente absorvida, fazendo do maiô e do duas-peças, três dedos acima do umbigo, os trajes de banho feminino, que, trazem a assinatura de diversas marcas já consagradas. Os biquínis começam a ser popularizados a partir da década de 1960, ainda assim com a lateral bastante larga, em geral eram produzidos de modo caseiro ou trazidos, como novidade, da Europa.

Na década de 60 os duas-peças já tinham dado lugar aos biquínis, que deixavam a barriga à mostra, porém ainda com as laterais largas, que garantiam a cobertura de toda a nádega, condicionando uma nova forma para a peça. Esse é o resultado que garante o diferencial do biquíni carioca: a parte da frente diminui e a forma final da parte de baixo do biquíni se aproxima da forma da tanga, sendo que na parte de trás a curva que cobre as nádegas ao invés de ser côncava como até então, agora se apresenta convexa, deixando um pouco mais de pele à mostra.

A moda foi lançada, não se sabe exatamente dar um nome a seu autor, são muitas as versões de autoria para o biquíni carioca que se aproxima de uma tanga. Alguns dizem que foi a modelo Rose di Primo quem puxou primeiro o biquíni na direção do quadril; outros, a atriz Maria Zilda. Contam também que foi um italiano, que resolveu fabricar as peças de modo que não fosse necessário enrolar do lado, na altura dos quadris. E até a versão de que ele surgiu fruto de um erro de produção dos irmãos Azulay, donos respectivamente de marcas de roupa que fizeram história na moda carioca, a Yes Brasil, de Simon, e a Blue Man, de moda praia, do David.

Sem dúvida, com o aparecimento da Lycra nos anos 1960, que paulatinamente substituiu a Helanca, foi possível melhorar o caimento e a aderência dos biquínis ao corpo. No entanto, o aparecimento do novo tecido em malha exigiu aperfeiçoamento 
técnico em relação à modelagem, em função de sua maior elasticidade. A partir de então, o mercado decodificou a modelagem que requer resolver, no plano, várias curvas em diferentes níveis.

Assim como um engenheiro deve calcular a estrutura de modo a contemplar um bom desenho para uma ponte, o modelista deve calcular a modelagem da parte de baixo de um biquíni, que deve cobrir os pelos pubianos, contornar a virilha, passar por entre as pernas e, por fim, cobrir os glúteos, conformando curvas de modo a liberar o movimento das pernas. Tarefa nada fácil - cada detalhe do traçado influenciará a resolução formal e funcional da peça. E o mesmo trabalho deve ser empreendido para a modelagem da parte que cobre os seios. A cada modelagem, um traçado, e, a cada traçado, um modelo diferente.

A moda praia brasileira inovou, e os biquínis nunca mais foram os mesmos depois das tangas, da asa-delta e do fio dental.

\section{CONCLUSÃO}

Entendemos que no Brasil, objetos vestimentares são contingenciados por vetores específicos da espacialidade, o que resulta em uma corporeidade específica que se imprime na cultura brasileira. No caso específico do biquíni, esta característica torna-se bastante evidente na cultura carioca, e, ao ser utilizado na paisagem da praia do Rio de Janeiro, transforma-se, em moda genuína, pois adquire em sua estrutura e em seu uso características específicas do sítio de pertencimento.

Das areias brasileiras, mais especificamente das areias cariocas, para o mundo, essa moda se constituiu genuína e contingente. Ela é fruto das relações das pessoas e de seus corpos com a geografia local e das diversas camadas da conformação do povo brasileiro. Ela é inovadora enquanto objeto de moda, mas também no modo como ela se instituiu.

A inovação se deu na praia, sob céu aberto, aos olhos de todos, em um tempo definido. Não foi de autoria de um ou de outro especificamente, surgiu do diálogo, dos anseios de uma geração, que vivia aquele determinado momento, que ansiava pela liberdade, que buscava romper com o estabelecido, e que procurava uma identidade própria na tentativa de constituir algo genuíno e próprio.

Destarte, o biquíni carioca não representava mais o sentido inicial da ousadia dos franceses, mas, sim, a liberdade e simplicidade de nossos antepassados indígenas.

\section{REFERÊNCIAS}

CASTRO, Ruy. Chega de saudade. São Paulo: Companhia das Letras, 1999.

CAUQUELIN, Anne. A invenção da paisagem. São Paulo: Martins Fontes, 2007.

CHACAL. Posto nove, pedaço de mau caminho. Coleção Cantos do Rio (Rio Arte). Rio de Janeiro: Relume Dumará, 1998.

CORBIN, Alain. O território do vazio: a praia e o imaginário ocidental. São Paulo, Companhia das Letras, 1989.

ELIAS, Norbert. O processo civilizador: uma história dos costumes. Rio de Janeiro: Jorge Zahar Ed., 1993, v. II. 
IWATA, Nara; DEL RIO, Vicente. The Image of the Water front in Rio de Janeiro: Urbanism and Social Representation of Reality. Journal of Planning Education and Research, 24.2, 2004, pp. 171-183. Disponível em: <http://works.bepress.com/ vdelrion/5> Accesso: Abril de 2013.

KNIERBEIN, Sabine. Playas urbanas como espacios públicos: el caso Rio de Janeiro. Disponívelem:<http://www.uniweimar.de/architektur/raum/publikationen/Playasurba nascomoespspub_sknierbein.pdf> Acesso: março de 2012.

LEROI-GOURHAN, André. Êvolution et techniques, milieu et techniques. Paris: Albin Michel, 1971 vol.2.

ORTIZ, Fernando. Contrapunto cubano del tabaco y el azucar. Havana: ed. Ciências sociais, 1991.

TUAN, Yi-fu. Espaço e Lugar - a Perspectiva da Experiência. São Paulo: Editora Eduel, 2013.

VILLACA, N. M. S. . Moda e periferia: negociações midiáticas. In: Ana Cláudia de Oliveira; Kathia Castilho. (Org.). Corpo e moda: por uma compreensão do contemporâneo. 1ed.São Paulo: Estação das Letras e Cores, 2008.

ZAOUAL, Hassan. Nova Economia das Iniciativas Locais. Rio de Janeiro. DP\&A, Consulado Geral da França, COPPE-UFRJ, 2006. 